\title{
Premier not alone in venturing south of the 49th parallel for medical treatment
}

Published at www.cmaj.ca on Mar. 8

$\mathrm{N}$ ewfoundland and Labrador Premier Danny Williams' foray to the Mount Sinai Medical Center in Miami, Florida, for mitral valve surgery has engendered the predictable array of responses, including outrage from cardiac surgeons who felt he slighted their capabilities, as well as broadsides at the quality of Canada's health care system from both sides of the border.

Yet, it is equally clear from an informal CMAJ canvas that Williams' decision is hardly unique. Some Canadians choose to venture south for treatment, while others are sent below the 49th parallel by their physicians and provincial health systems for reasons ranging from capacity to wait times.

In fact, according to the $C M A J$ canvas of provincial health departments, at least 160000 medical services or treatments were performed on Canadians outside the country over the past three years, most in the United States.

At least part of the reason for the shuffle south is the difference in the way in which Canada and the US ration medical services, says Terry Sullivan, president and chief executive officer of Cancer Care Ontario and professor of health policy management at the University of Toronto in Ontario.

The US system, Sullivan says, provides care based on capacity to pay, while Canada provides care based on necessity.

Because of population density alone, the US performs more of every procedure and more unnecessary procedures than Canada, Sullivan adds. But the bulk of those procedures are for people who can afford them, he adds, noting that 48 million US residents are uninsured and another 25 million are underinsured.

Canada's rationing principles, by contrast, lead to some traffic across the

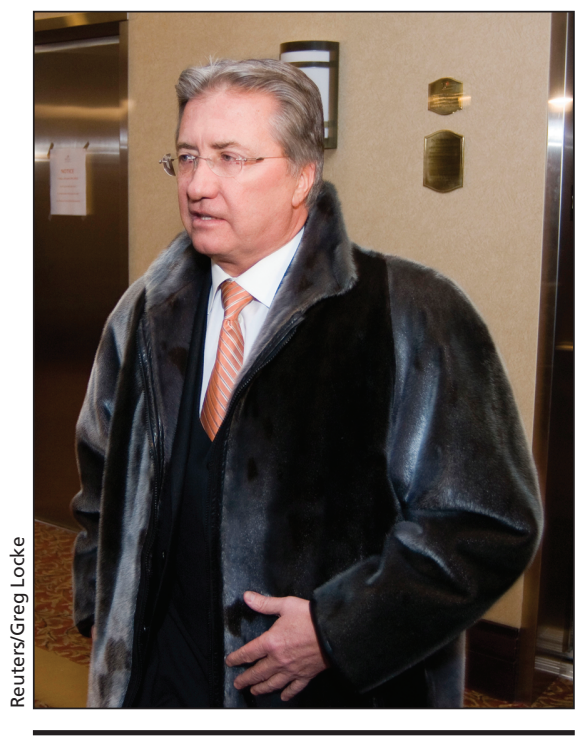

"This is my heart. It's my health. It's my choice," Newfoundland and Labrador Premier Danny Williams told reporters in defending his decision to seek mitral valve surgery at the Mount Sinai Medical Center in Miami, Florida, rather than within Canada.

border and often cost provincial governments millions of dollars.

But that is not an indicator of failure within the Canadian system, Sullivan insists.

Official or national data on medical services obtained out-of-country is at best incomplete. The Canadian Institute of Health Information maintains some data but that is often based on checkerboard provincial statistics. Because provinces don't all collect the same information about out-of-country health care spending, cross-Canada comparisons are difficult. For instance, Prince Edward Island and Quebec do not distinguish between out-of-province and out-of-country claims.

Some provinces only record information about treatments received with prior approval applications. For example, New Brunswick's Department of Health was only able to confirm that the province spent approximately $\$ 764000$ for prior-approved hospital and medical services to 43 patients in the US. Other provinces include information about reimbursed out-of-country emergency services (required, for example, during vacations) in their total out-of-country expenditures.

Such variations in data collection are not unusual, says Joseph D'Cruz, the academic director of health care executive programs at the Rotman School of Management at the University of Toronto in Ontario.

Provincial data discrepancies, and poor national data standards, are some of the biggest challenges associated with monitoring the Canadian health care system, he says. "It is very frustrating. It is not possible to do good interprovincial or international comparisons in Canada."

Despite these discrepancies, available statistics indicate that Ontario is the biggest out-of-country spender of the provinces. In fiscal year 2008/09, Ontario spent $0.3 \%$ of its $\$ 42.6$-billion health care budget on out-of-country treatment, totalling \$127.9 million. With a projected 2009 population of 13 million, that amounts to roughly $\$ 9.79$ per capita.

Manitoba is a close second, paying $\$ 7.4$ million in out-of-country medical and hospital payments in fiscal $2008 / 09$, or roughly $0.18 \%$ of the province's \$4.1-billion health care bill. In addition, Manitoba Health provides transportation subsidies for approved referrals.

All other provinces - at least, those for which calculations are available are spending considerably less on outof-country treatment.

Saskatchewan, for example, spent $\$ 3.1$ million in fiscal 2008/09 on insured treatments outside Canada, or about $0.07 \%$ of its $\$ 3.976$-billion health care bill.

The difference in spending levels might be explained by the types of procedures commonly referred out-of- 
country by each province. Ontario and Manitoba both list cancer treatment and bariatric surgery as two of the top procedures for which people are sent out of Canada, and two of their most costly. In fiscal 2008/09, just over 2000 weightloss surgeries cost Ontario $\$ 50.6$ million, while 633 cancer patients cost it $\$ 24.1$ million. Combined, the two categories accounted for more than half of Ontario's out-of-country spending.

Ontario has adopted several initiatives to reduce those numbers, says Andrew Morrison, spokesman for the Ontario Ministry of Health and Long-Term Care. The province has invested $\$ 75$ million in expanding domestic capacity to perform bariatric surgery and plans to implement measures to reduce the amount spent on cancer treatment and genetic testing, for which Ontario shelled out $\$ 9.8$ million for 5446 out-of-country cases.

British Columbia similarly found that it's possible to reduce of number of patients sent out of country, when in fiscal 2007/08, it expanded bed capacity for specialized perinatal services, and found that out-of-country expenses dropped to $\$ 16.04$ million from $\$ 18.71$ million within a year. In fiscal 2007/08, there were 78 patients sent out of country for neonatal care. That dropped to 19 cases in fiscal 2008/09. Thus far this year, only four patients have been transferred out of country.

All the numbers, though, account for just a portion of treatments performed outside Canada's borders, as attested by Williams' journey. Most provinces cover only emergencies and elective surgeries not available within their borders or within Canada, and those are generally paid at the same rate as they would be in the home province. There are slight variations between provincial policies, but most require prior approval and a physician's referral for elective services outside the country.

In Alberta, for example, the Out-ofCountry Health Services Committee considers applications for services unavailable in Canada and in fiscal 2008/09, approved 79 applications, valued at $\$ 3.72$ million, or about $0.03 \%$ $\$ 1.01$ per capita - of Alberta Health and Wellness' \$12-billion budget.
Beyond that lie out-of-country procedures paid for out of pocket by Canadians. To avoid lengthy waiting lists, some patients choose to go through brokers - private companies that promise to arrange for procedures at lower costs.

Richard Baker, president of Timely Medical Alternatives in North Vancouver, BC, brokers US procedures for about 100 Canadians a year. Baker says patients are generally seeking treatment in three areas: major spinal surgeries, cardiac procedures or orthopedic surgeries.

Yet not all patients going to the US approach a broker and it's therefore impossible to track them, the Canadian Institute for Health Information says.

That uncertainty, coupled with varying types of data collection among the provinces, make calculations regarding out-of-country medical treatment for Canadians very problematic. Brittany Hinds, Ottawa, Ont.

DOI:10.1503/cmaj.109-3199 